\title{
Pericardial instillation of streptokinase in purulent pericarditis
}

\author{
*Thushara Milinda Rodrigo ${ }^{1}$, Duminda Samarasinghe ${ }^{2}$, Ruwan Morawakkorala ${ }^{2}$
}

Sri Lanka Journal of Child Health, 2019: 48(4): 353-356

DOI: http://dx.doi.org/10.4038/sljch.v48i4.8834

(Key words: Purulent pericarditis, streptokinase)

\section{Introduction}

Purulent pericarditis is a potentially life threatening condition with a mortality rate of $20-30 \%{ }^{1}$. We describe a clinical case of purulent pericarditis which was successfully treated with a combination of local instillation of streptokinase and parenteral antibiotics.

\section{Case report}

Ms. S, a 12-year-old previously healthy child, presented to the local hospital with a 4-day history of fever without an apparent focus. She was the fourth child of healthy non consanguineous parents. She did not have weight loss or a chronic cough, but was a close contact of a grandfather, who had an unresolving cough for 4 months. She was a developmentally normal child with age appropriate immunization.

On admission to the local hospital, the girl was febrile, tachycardic with marginally low blood pressure and had features of respiratory distress. Her heart sounds were muffled but a pericardial rub was evident on examination. Ms. S's initial investigations revealed a white blood cell (WBC) count of $23.61 \times 10^{3} / \mu 1$ with $81.5 \%$ neutrophils, a Creactive protein (CRP) of $144 \mathrm{mg} / \mathrm{dl}$ and an erythrocyte sedimentation rate (ESR) of $48 \mathrm{~mm} / \mathrm{hr}$.

\footnotetext{
${ }^{1}$ Senior Registrar in Paediatric Cardiology,

${ }^{2}$ Consultant Paediatric Cardiologist, Lady Ridgeway Hospital for Children, Colombo, Sri Lanka,

*Correspondence: ptmrodrigo@gmail.com

orcid.org/ 0000-0002-9197-6871

(Received on 08 February 2018: Accepted after revision on 16 March 2018)

The authors declare that there are no conflicts of interest

Personal funding was used for the project.

Open Access Article published under the Creative

Commons Attribution CC-BY (CC)
}

Her chest X-ray / globular heart (figure 1) and ECG showed evidence of pericarditis (figure 2). She had undergone an echocardiogram at the local hospital, which demonstrated thickened pericardium with multiple septae.

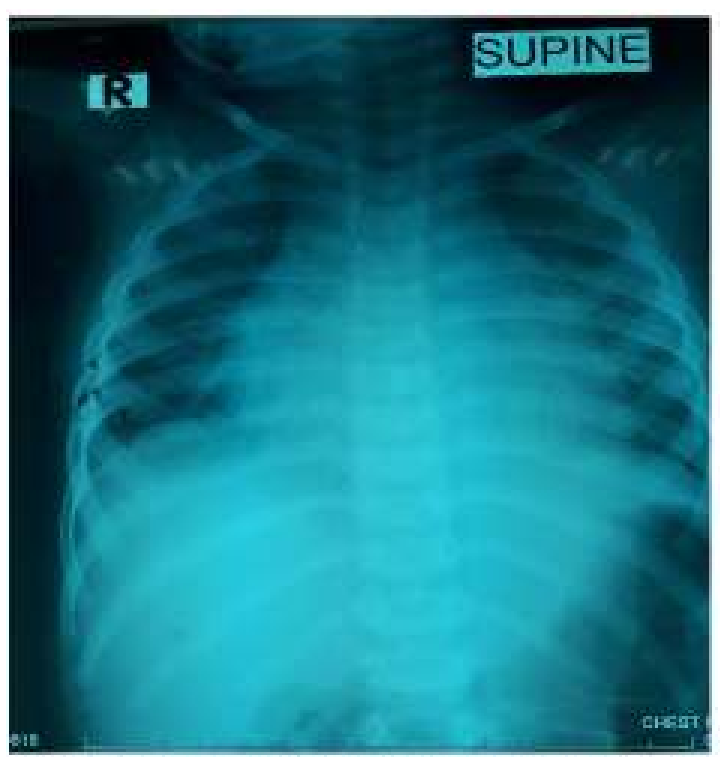

Figure 1: Chest $x$-ray showing globular heart

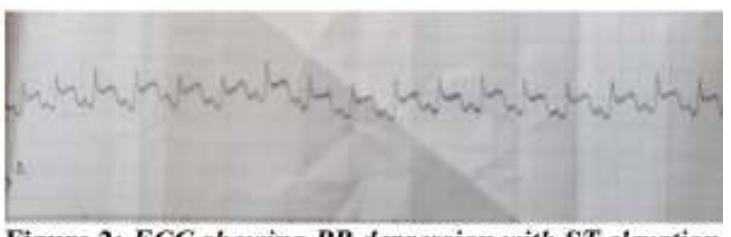

Figure 2: ECG showing PR depression with ST elevation

She was started on parenteral antibiotics with cefuroxime, gentamycin, cloxacillin and vancomycin, where frequent alterations were done due to the poor clinical response (figure 3 ). 


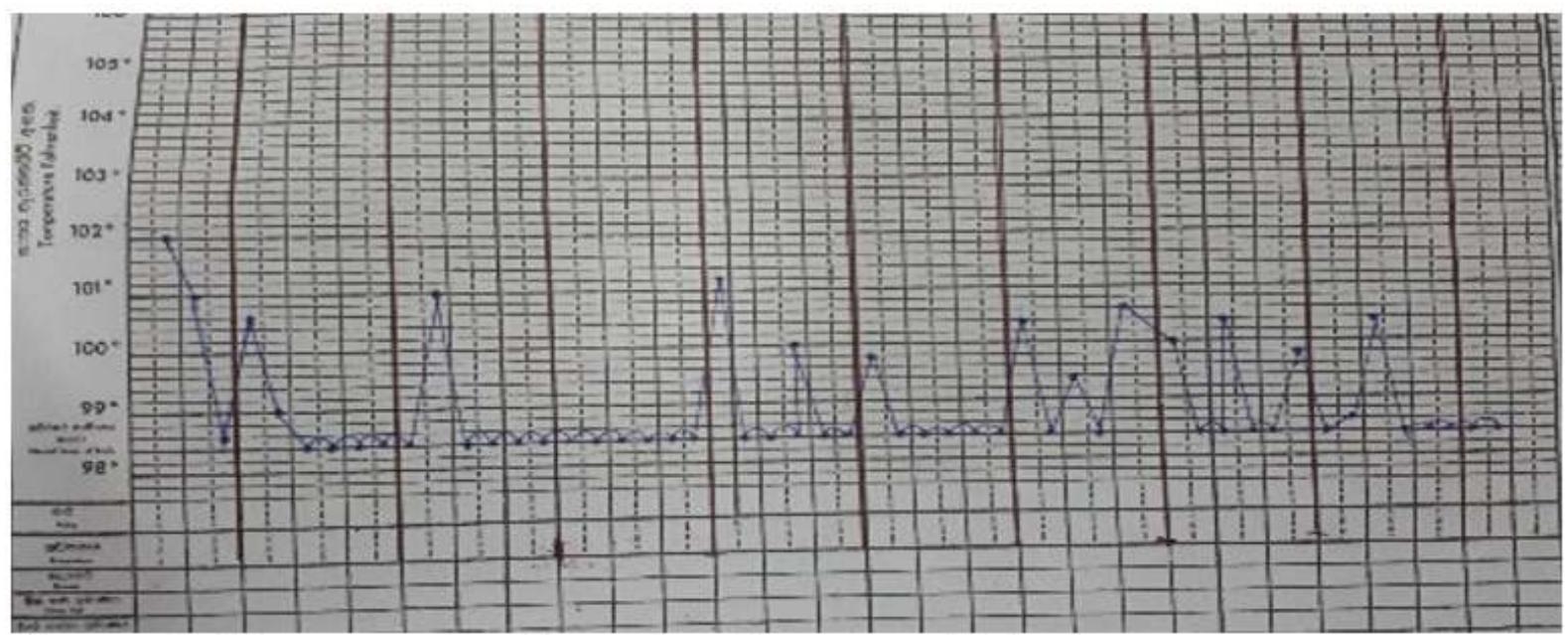

\section{Figure 3: Temperature chart showing poor clinical response to treatment}

Subsequently, child was transferred to the cardiology unit at Lady Ridgeway Hospital (LRH) for the further management. On admission to our unit at LRH, the child was ill looking, febrile and irritable with stable haemodynamic parameters. Her cardiovascular examination revealed muffled heart sounds without a pericardial rub. There was no lymphadenopathy or hepatosplenomegaly. The following investigations were done (Table 1).

Echocardiogram performed at LRH showed thick pericardial effusion with normal cardiac function (figure 4).

Table 1: Investigations carried out in the cardiology unit at Lady Ridgeway Hospital

\begin{tabular}{|l|c|c|c|}
\hline \multicolumn{1}{|c|}{ Investigation } & $\mathbf{1 3 / 0 9 / 2 0 1 7}$ & $\mathbf{2 3 / 0 9 / 2 0 1 7}$ & $\mathbf{0 1 / 1 0 / 2 0 1 7}$ \\
\hline White blood cell count $(/ \mu \mathrm{l})$ & 27.7 & & 12.6 \\
\hline Neutrophils & $70.6 \%$ & & $26 \%$ \\
\hline Lymphocytes & $18.6 \%$ & & $69 \%$ \\
\hline C-reactive protein $(\mathrm{mg} / \mathrm{dl})$ & 42 & 65.3 & \\
\hline Erythrocyte sedimentation rate $(\mathrm{mm} / \mathrm{hr})$ & 70 & 91 & 48 \\
\hline Blood picture & Sepsis & & \\
\hline Blood culture & No growth & & \\
\hline
\end{tabular}
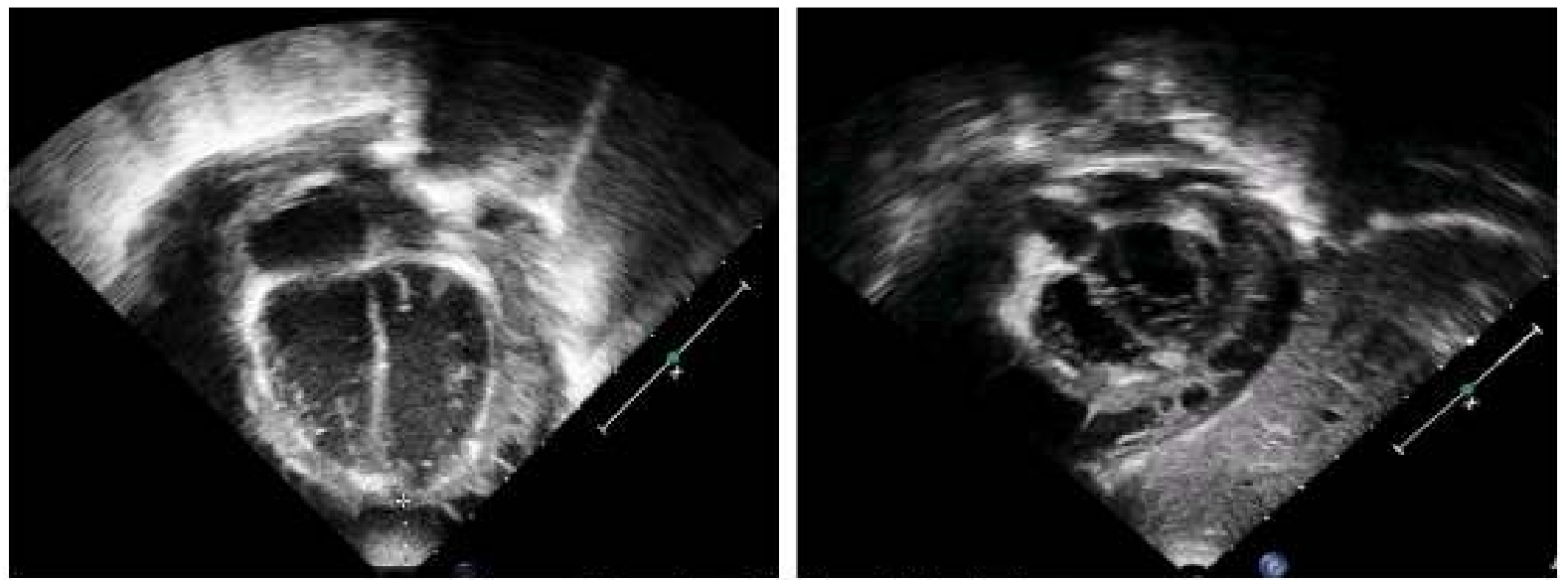

Figure 4: Loculated pericardial effusion

Pericardial aspiration was done and fluid analysis revealed purulent gel like material on macroscopy with $4+$ of pus cells and protein of $4.446 \mathrm{~g} / \mathrm{dl}$. However, bacterial and fungal cultures were negative with negative tuberculosis (TB) polymerase chain reaction (PCR) (Xpert TB). Her
Mantoux test was negative and the ultrasound scan (USS) of the abdomen was normal. Pericardial fluid TB culture and serum lactate dehydrogenase (LDH) was normal. 


\section{Management}

The already started antibiotics were continued, but changes were made due to ongoing fever and rising inflammatory markers, after liaising with the microbiology team. Ultimately, she was given 28 days of parenteral vancomycin and 21 days of parenteral meropenem.

Since there was purulent pericarditis with echocardiographic evidences of development of constrictive pericarditis with thick pericardium, therapeutic options of surgical pericardiectomy and intrapericardial instillation of streptokinase was considered. However, considering the risk of surgical pericardiectomy local instillation of streptokinase was attempted after a literature review.
A dose of $18,000 \mathrm{IU} / \mathrm{kg}$ of streptokinase was instilled into the pericardium as a daily dose and the drug was left in the pericardium for an hour followed by drainage under strict cardiovascular monitoring for 5 days. During the $2^{\text {nd }}$ and $4^{\text {th }}$ doses the child developed sudden transient episodes of bradycardia with apnoea after excessive crying, which improved with brief bag and mask ventilation. The response was monitored with follow up echocardiogram, inflammatory markers and clinical parameters. Ms. $\mathrm{S}$ responded well to the parenteral antibiotic regime which was coupled with local instillation of streptokinase, opening up a new therapeutic approach to the management of purulent pericarditis (Figures 5 and 6).

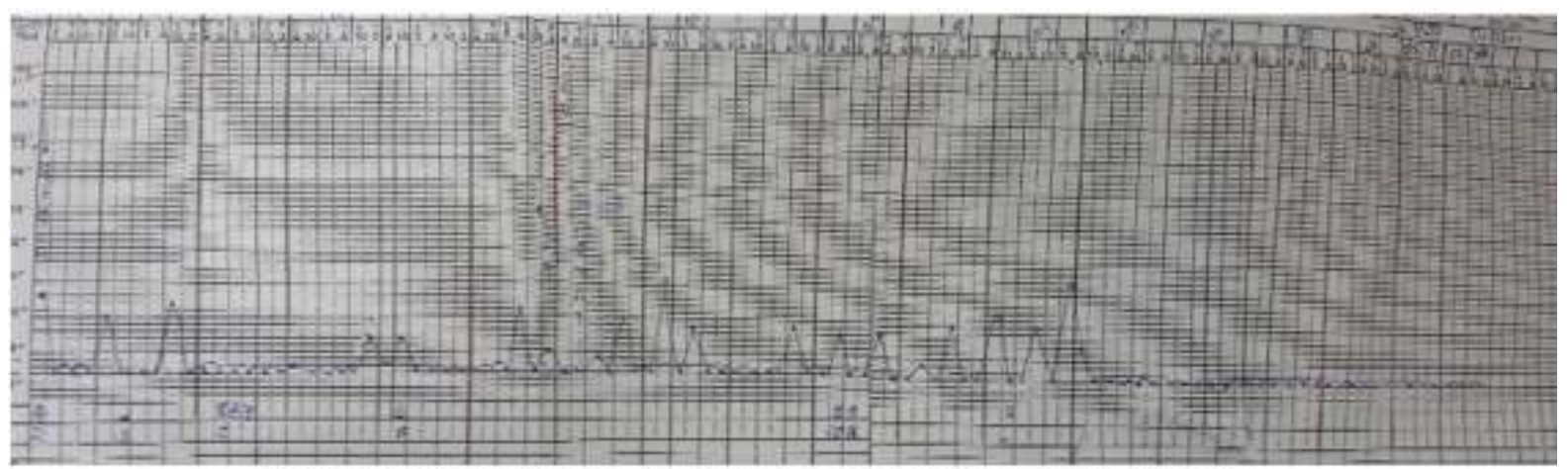

Figure 5: Temperature chart showing good response to treatment

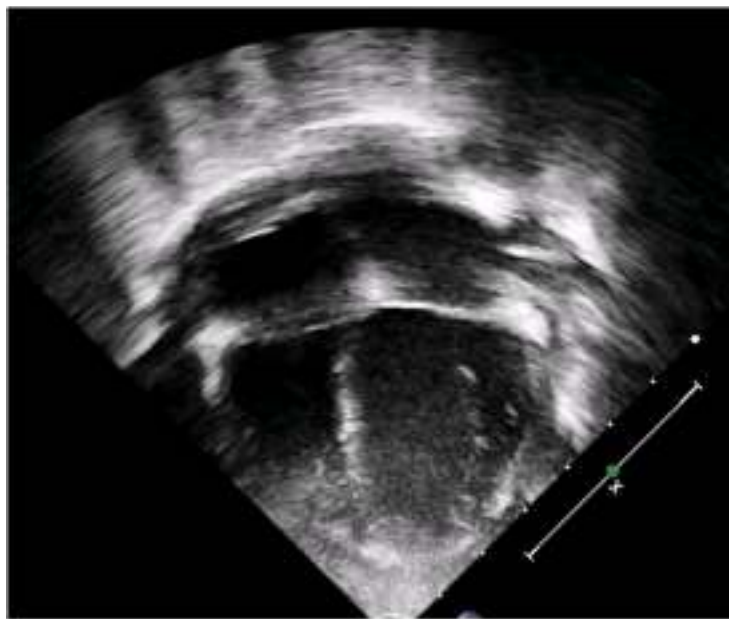

Figure 6: Absence of pericardial effusion

\section{Discussion}

Several treatment options, including aspiration, pericardiotomy, operative evacuation with pericardiectomy, subxiphoid drainage and irrigation are used to manage simple and loculated purulent pericarditis $^{2}$. Current treatment of choice for purulent pericarditis is a combination of drainage and intravenous antibiotics.

Pericardial irrigation with streptokinase and streptodornase was first documented more than 40 years ago ${ }^{3}$. Despite its well documented success the method was rarely used in the management of purulent pericarditis. In our case we have demonstrated the efficacy of the local instillation of streptokinase in loculated purulent pericarditis highlighting the value of an old remedy. Purulent pericarditis leads to the reduction off fibrinolytic activity leading to extensive fibrin deposition over mesothelial surface ${ }^{4}$. Streptokinase acts by activating the fibrinolytic system and brings about dissolution of blood clots and the fibrinous component of exudates facilitating the drainage.

The described approach has several advantages over surgical techniques.

- Avoidance of extensive surgical procedures like thoracotomy which carries significant mortality and morbidity.

- Minimal incidences of constrictive pericarditis.

- Cost effectiveness and relatively less labor intensive.

Local instillation of streptokinase is not without side effects. Juneja et al described submitral aneurysmal formation during their case series, attributed to the high local concentration of streptokinase leading to interstitial collagen breakdown ${ }^{5}$. Allergy is a wellknown side effect even after the repeated doses of local instillation. Another life threatening adverse 
effect described in the literature is major hemorrhage leading to haemorrhagic tamponade ${ }^{5}$. It is also important to remember the risk of cardiac tamponade if there is suboptimal drainage following local administration. However, brief episodes of apnoea with bradycardia, following excessive irritability, which responded well to bag and mask ventilation is not described in the literature. We considered it as a probable reaction to the drug but exact physiological basis is not clear.

Although Ms. S responded well to the combined antibiotic and local instillation of streptokinase, patients who do not respond to the particular therapy needs pericardiectomy for the complete eradication of infection and prevention of constrictive pericarditis. According to our experience with this clinical scenario we consider the local instillation of streptokinase combining with parenteral antibiotic represent a safe, conservative management option for purulent pericarditis.

\section{References}

1. Klacsmann PG, Bulkley BH, Hutchins GM: The changed spectrum of purulent pericarditis: an 86 year autopsy experience in 200 patients. America Journal of Medicine 1977; 63:666-73. https://doi.org/10.1016/00029343(77)9015 $0-4$
2. Majid AA, Omar A. Diagnosis and management of purulent pericarditis: experience with pericardiectomy. Journal of Thoracic and Cardiovascular Surgery 1991; 102:413-7.

PMid: 1881180

3. Wright LT, Smith DH, Rothman M, Metzger WI, Quash ET. Use of streptokinase-dornase in certain surgical conditions. Journal of the International College of Surgeons 1951; 15:286-98.

PMid: 14824581

4. Leak LV, Ferrans VJ, Cohen SR, Eidbo EE, Jones M. Animal model of acute pericarditis and its progression to pericardial fibrosis and adhesions: ultrastructural studies. American Journal of Anatomy 1987; 180:373-90.

https://doi.org/10.1002/aja.1001800408 PMid: 3425565

5. Juneja $\mathrm{R}$ et al. Intrapericardial streptokinase in purulent pericarditis; Archives of Disease in Childhood 1999; 80:275-7.

https://doi.org/10.1136/adc.80.3.275 PMid: 10325712 PMCid: PMC1717856 